\title{
Features of Calculation of Consolidation Process of Weak Saturated Soils in View of Their Plastic Properties
}

\author{
Alexey Golubev ${ }^{1}$, Alexey Savchenko ${ }^{1}$, Luka Akimov ${ }^{1}$, Artem Frolov ${ }^{1, a}$ and Vladimir Lvov ${ }^{1}$ \\ ${ }^{1}$ Peter the Great Saint-Petersburg Polytechnic University, 29 Polytechnicheskaya st., St.Petersburg, 195251, \\ Russian Federation
}

\begin{abstract}
Issue of construction of facilities in areas of weak saturated soils is becoming particularly relevant in recent years. This problem applies especially to objects of oil and gas industry. Saturated soils are characterized by a filtration anisotropy, an inhomogeneity and an ability to liquefy in violation of their structure because of water content. Therefore, the study of bearing capacity of such soils in the process of consolidation has significant practical importance in ensuring the reliability of structures. The formulation, the method and the algorithm for calculating the stress-strain state of weak saturated soils is described in this article. Solution of the consolidation task is based on the model of body forces of threecomponent soil considering the elastic-plastic deformation of its skeleton. Some results of calculations have been shown in this article.
\end{abstract}

\section{Introduction}

The Florin-Bio's model of body (volumetric) forces is used to solve the problem of consolidation which reduces to the definition of time-varying stress-strain state of saturated soils. This model considers the three-dimensional interaction forces between the solid, liquid and gaseous components of soil during their relative movement in compaction process. The Florin-Bio's theory postulates that soil is the continuous medium wherein all components are continuously distributed over the volume.

The complete system of equations of the consolidation task involves [1-4]:

The equilibrium equations

$$
\sigma_{i j, i}+\delta_{i j} P_{i j}+F_{i}=0,
$$

The Cauchy's geometrical relationship

$$
e_{i j}=\frac{1}{2}\left(u_{i j}+u_{j i}\right)
$$

The physical equation for soil skeleton

$$
\sigma_{i j}=D_{i j k l} \cdot e_{x l}
$$

\footnotetext{
${ }^{a}$ Corresponding author: artemfrolov007@mail.ru
} 
The consolidation equation

$$
-u_{i, j}+\beta \cdot p=\left(\frac{k_{i j}}{\gamma_{b}} p, i\right) i
$$

In these equations $e_{i j}, \sigma_{i j}, k_{i j}$-components of tensors of deformations, tensions in the skeleton of the soil and the soil impermeability (filtration); $F_{i}, U_{i}$ - components of vector body forces and displacements, $\mathrm{p}$ is the overpressure in the pore water, $D_{i j k l}$ - components of physical matrix of the deformation of the soil skeleton, $\gamma_{b}$ - unit weight of water, $\delta_{i j}$ - the Kronecker delta $\left(\delta_{i j}=1\right.$ when $i=j, \delta_{i j}=0$ when $\left.i \neq j\right)$.

The coefficient $\beta$ in Eq.4, interpreted by Florin as the coefficient of the volume compressibility of three-component soil owing to a presence of entrapped gas [1], is a variable which changes as pressure in the pore water $p$ and volumetric soil deformation $e_{v}$ vary:

$$
\beta=\beta_{0} \frac{p_{0}}{\left(p_{0}+p\right)^{2}\left(1+e_{1}\right)},
$$

where $p_{0}$ - the initial pressure in the water, including atmospheric pressure; $\beta_{0}$ - the initial coefficient of volumetric compressibility, which is determined by the initial values of porosity of the soil $n_{0}$, the degree of soil saturation $S_{r 0}$ and the solubility coefficient of gas $\mu$ (for air $\mu=0.0245)$ :

$$
\beta=n_{0}\left(\mu S_{r_{0}}-S_{r_{0}}+1\right)
$$

\section{Solution of a task}

The analysis of experimental data and theoretical studies shows that the process of deformation of the soil skeleton could be satisfactorily described from the point of models of elastically perfectly plastic Prandtl body [5-7]. Using this model compared with other more complex elastoplastic models [8-12] greatly simplifies the solution of the task and does not requires additional experimental parameters which characterize the nonlinear deformation of soil.

Deformations are considered as elastic in the pre-limit stress state of soil and determined by the generalized Hooke's law using as characteristics the unit of the overall deformation and Poisson's ratio [13-15]. In the limiting condition, which is determined in accordance with Coulomb's yield condition [16], physical equations Eq.3 take the form of incremental ratio $d \sigma_{i j}=D^{p}{ }_{i j k l} \cdot d e_{k l}$, which represents a process of plastic deformation with the sequence of small deformations embroadening. The elements of $D^{p}{ }_{i j k l}$ matrix have been obtained for the associated law of plastic flow [17].

The solution of the task of stress-strain state of saturated consolidating bases, based on the model of body forces in view of elastic-plastic deformation of the soil skeleton, is possible only by numerical methods involving computers to implement them [18-21]. In this article the finite element method has been used in the most common variant of the method of displacements [22]. The main provisions and the relations of the FEM allow to reduce the system of differential equations Eq.1 - Eq.4 to the elementary system of algebraic equations (represented in matrix form) which could be solved by the explicit difference scheme relative to the unknown vector of nodal displacements $U_{t+\Delta t}$ and the excess pore pressure $P_{t+\Delta t}$ at time point $t+\Delta t$ : 


$$
\begin{aligned}
& K_{t+\Delta t} \cdot U_{t+\Delta t}+C \cdot P_{t+\Delta t}=K_{t} \cdot U_{t}+C \cdot P_{t}+\Delta F_{\Delta t}, \\
& C^{T} \cdot U_{t+\Delta t}+\left(M-\frac{\Delta t}{2} \cdot H\right) P_{t+\Delta t}=C^{T} U_{t}+\left(M+\frac{\Delta t}{2} H\right) \cdot P_{t} .
\end{aligned}
$$

The generalized matrices of stiffness $K$, gas deformation $M$, filtering $H$ are formed from relevant matrices of each element of the system. A triangular simplex has been taken as a finite element. A triangular simplex is an element with nine degrees of freedom for which all the necessary matrices in finite element analysis have been obtained. The development of the plastic deformation region is defined with the transition of finite elements to the limit state because the stress state in such elements is homogeneous.

The programs which were designed for computers ES 1061and PCs of IBM type allow us to calculate the stress-strain state of inhomogeneous saturated soil masses under conditions of plane deformation during a random loading over time.

It is required to establish the input parameters of soils: the modulus of deformation $E$, the Poisson's ratio $v$, the soil adhesion $C$, the angle of internal friction $\varphi$, the unit weight of soil $\gamma$, the coefficient of lateral pressure $\xi$ (to determine the initial domestic stress state), the filtration coefficient $K_{f}$, the initial coefficient of volume compressibility $\beta_{0}$. The position of ground water level is given in addition to the boundaries of homogeneous soil areas.

The generalized matrix of Eq. 8 could be built considering saturated and unsaturated stress state of the soil under the condition of Coulomb:

$$
f=\sqrt{\left(\sigma_{x}-\sigma_{y}\right)^{2}+4 \tau_{x y}^{2}}+\left(\sigma_{x}+\sigma_{y}\right) \cdot \sin \varphi-2 c \cdot \cos \varphi
$$

For $f<0$ the soil is in the pre-limit (elastic) state and its deformability is determined by Eq.3 in which the physical matrix $D_{i j k l}$ is equal to the elastic matrix $D^{e}{ }_{i j k l}$ :

$$
D_{i j k l}^{e}=\frac{E}{(1+v)\left(1-v-2 v^{2}\right)}\left|\begin{array}{ccc}
1-v^{2} & v(1+v) & 0 \\
v(1+v) & 1-v^{2} & 0 \\
0 & 0 & \left(1-v-2 v^{2}\right) / 2
\end{array}\right| .
$$

For $f=0$ the soil goes into limiting (plastic) state and elastic matrix is replaced by plastic $D^{p} i j k l$ elements of which depend on the level of the achieved stress state:

$$
D_{i j k l}^{p}=D_{i j k l}^{e-D_{i j k l}^{e}} \cdot \frac{\left(\frac{\partial f}{\partial \sigma}\right) \cdot\left(\frac{\partial f}{\partial \sigma}\right)^{T} \cdot D_{i j k l}^{e}}{\left(\frac{\partial f}{\partial \sigma}\right)^{T} \cdot D_{i j k l}^{e} \cdot\left(\frac{\partial f}{\partial \sigma}\right)} .
$$

The calculation process at each time step is built on the following iterative scheme. On the first iteration the system Eq. 6 is solved at the time point $t+\Delta t$ with $K_{t+\Delta t}=K_{t}$. By the value of the displacement increment $\left(U_{t+\Delta t}-U_{t}\right)$ during the time $\Delta t$ the increment of deformation $\Delta e_{i j}$ is determined, which is divided into $N$ sections. At each new n-th section the increment of stress is determined by $\Delta \sigma_{i j}^{n}=d_{i j k l} \cdot \Delta e_{k l}^{n}$. If the Coulomb yield function $f\left(\sigma_{i j}^{n-1}\right)$ does not exceed a specified limit of transition to the plastic state $(\varepsilon)$, then $d_{i j k l}=d^{e}{ }_{i j k l}$; if $\varepsilon \leq f\left(\sigma_{i j}^{n-1}\right) \leq 0$, then $d_{i j k l}=d^{e}{ }_{i j k l}\left(\sigma_{i j}^{n-1}\right)$. In case of the transition to the "beyond" state, when $f\left(\sigma_{i j}^{n-1}\right)>0$, the 
number of sections $N$ is doubled and previous calculations are repeated. The matrix $D_{i j k l}$, connecting the increment of stress $\Delta \sigma_{i j}$ and the deformation $\Delta e_{k l}$ during the time $\Delta t$ is determined by the expression:

$$
D_{i j k l}=\frac{1}{N} \cdot \sum_{n+1}^{N} d_{i j k l} .
$$

Then the stiffness matrix of the system is calculated and Eq. 8 is re-solved. Iterative process ends when the difference between the values of the angular displacement and the pore pressure, which were obtained in two successive iterations, is not greater then specified error.

Some results of calculations of the stress-strain state of $4 \mathrm{~m}$. thick homogeneous soil base loaded with uniformly distributed vertical load $q$ with width of $26.2 \mathrm{~m}$. are given below. The calculation scheme and boundary conditions are presented in Fig.1.
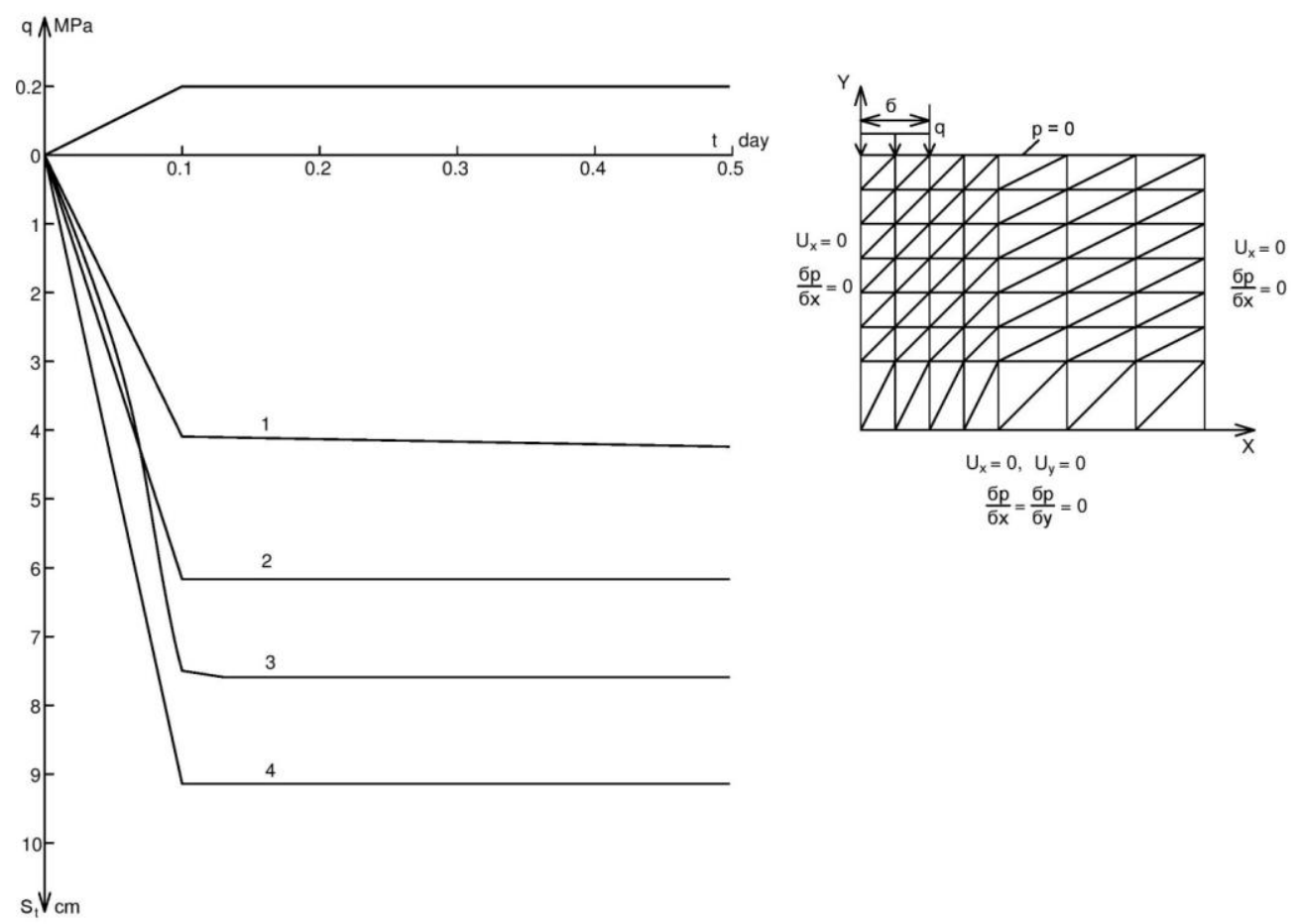

Figure. 1 Calculation scheme of the stress-strain state of homogeneous soil base and boundary conditions.

The soil has the following characteristics: $E=500 \mathrm{t} / \mathrm{m}^{2}, v=0.3, C=2.4 \mathrm{t} / \mathrm{m}^{2}, \varphi=15^{\circ}$, $\gamma=1.0 \mathrm{t} / \mathrm{m}^{3}$ (weighing of soil in water is considered), $\xi=0.43, K_{f}=0.001 \mathrm{~m} / \mathrm{day}, \beta_{0}=0$ (at full water saturation) or $\beta_{0}=0.03$ (at $n_{0}=0.41$ and $S_{r 0}=0.95$ ).

To analyze the effect of development of the plastic areas on the stress-strain state of soil consolidating the calculations were made using the elastic-plastic and the elastic model of the skeleton of the soil. In addition, calculations in these models were made for stable ground conditions when the overpressure in the pore water is equal to zero (no consolidation process). The figure shows the variation in time of the external load $q$ and the precipitation of the center point of the band loaded by $S_{t}$. Curves 1 and 2 were obtained for the elastic model (respectively in the absence $\left(\beta_{0}=0\right)$ and 
presence ( $\beta_{0}=0.03$ ) of gas). Curves 3, 4 - for the elastic-plastic model (respectively in the absence and presence of gas). As it could be seen, the consideration of the development of the field of limit state of stress significantly affects on the amount of setting.

Thus, at $t=0.1 d a y$, when the load has reached its maximum value, the ratio of the precipitate obtained by the elastic-plastic and the elastic models, $1.75\left(\beta_{0}=0\right)$ and $1.43\left(\beta_{0}=0\right)$; when $t=0.5 \mathrm{day}$, these values are respectively equal to 1.60 and 1.38 . The values of stabilized sediment $S *$ for elastic model are 7.95, for elastic-plastic model this values are equal to 9.48. At time point $t=0.5$ day the degree of consolidation, estimated by the ratio $S_{t} / S_{*}$, for fully saturated soil is equal to 0.65 (in elastic model), and 0.86 (in elastic-plastic model). In the presence of gas - 0.84 and 0.97 , respectively. Despite the fact that the degree of consolidation of gas containing soil is higher, compaction process itself is slower than in a fully water-saturated soil (Fig.1): the rate of sediment in the range of time $0.1-0.5$ is $0.58 \mathrm{~cm} /$ day (elastic model), $0.51 \mathrm{~cm} /$ day (elastic-plastic model). In water saturated state these values are equal to 2.08 and $1.65 \mathrm{~cm} /$ day, respectively.

\section{Conclusions}

The study of the consolidation process requires special attention in the calculation of bearing capacity of weak saturated soils. Presented results demonstrate that at calculations of stress-strain state of such soils it is necessary to consider their plastic properties. Designed calculation programs offer great opportunities to consider a nonlinear properties of stress-strain state of arrays of soils interacting with constructions. They could be used to predict the optimal mode of loads during the construction and operation of facilities.

\section{References}

1. V.A. Florin, Osnovi mehaniki gruntov (M. -L. Gosstroyizdat, St.Petersburg, 1961)

2. G. L. Martin, The consolidation process in a partially saturated clay (Abstract Ph.D, The University of Arizona, 1965)

3. L. D. Suits, T. C. Sheahan, B. Bai, Geotech. Test. J., 29, 289-297 (2006)

4. D. T. C. Yao, W. L. De Oliveira-Filho, X. C. Cai, D. Znidarcic, Intern. J. for Numer. and Analyt. Meth. in Geomech., 26, 139-161 (2002)

5. E.T.R. Dean, Intern. J. of Plast., 21, 513-571 (2005)

6. I. F. Collins, Intern. J. of Mech. Sc., 47, 493-508 (2005)

7. B. Loret, N. Khalili, Mech. of Mat., 34, 97-116 (2002)

8. S. López-Querol, J. A. Fernandez-Merodo, P. Mira, M. Pastor, Intern. J. for Numer. and Analyt. Meth. in Geomech., 32, 1431-1457 (2008)

9. Z. L. Wang, J. G. Wang, R. F. Shen, Comp. and Geosc., 86, 849-859 (2008)

10. C. Menéndez, P.J.G. Nieto, F.A. Ortega, A. Bello, Appl. Math. and Comput., 216, 458-476 (2010)

11. C. Menéndez, P.J.G. Nieto, F.A. Ortega, A. Bello, Appl. Math. and Comput., 49, 2002-2018 (2009)

12. Soodeh Samimi, Ali Pak, Comp. and Geosc., 46, 75-83 (2012)

13. P.G. Nicholson, Soil Improvement and Ground Modification Methods (Elsevier, Longford, 2015)

14. K. Soga, S.A. Jefferis, Contrib. to Geotech., 58, 441-448 (2008)

15. R. I. Borja, Comp. Meth. in Appl. Mech. and Eng., 193, 5301-5338 (2004)

16. A.M. Puzrin, Intern. J. of Solids and Struct., 38, 6815-6827 (2001) 
17. A. K. Bugrov, O reshenii smeshannih zadach teorii uprugosti i teorii plastichnosti gruntov (Base, foundation and soil mechanics. M., St.Petersburg, 1974)

18. H.W. Zhang, K.P. Wang, Z. Chen, Comp. Meth. in Appl. Mech. and Eng., 198, 1456-1472 (2009)

19. Z.Y. Ai, Z.Y. Cheng, J. Han, Intern. J. of Eng. Sc., 46, 486-498 (2008)

20. A. Ghassemi, A. Pak, H. Shahir, Comp. and Geotech., 37, 10-24 (2010)

21. K.H. Park, P.K. Banerjee, Comp. Meth. in Appl. Mech. and Eng., 191, 3233-3255 (2002)

22. L. Segerlind, Primenenie metoda konechnih elementov (M.: Mir, Moscow, 1979) 